\title{
The Absence of Soluble Antibacterial Inhibitors in Clostridium spp.
}

\author{
By G. BELYAVIN \\ The National Institute for Medical Research, Hampstead, London
}

SUMMARY: By a cup-plate method, the antibiotic activity of fluid cultures of 253 strains of spore-bearing anaerobic bacilli representing over sixteen Clostridium spp. was tested against one strain each of Mycobacterium phlei, Staphylococcus aureus, and Bacterium coli. Two strains of Clostridium sporogenes and two of Cl. bifermentans showed a weak and variable activity against Mycobacterium phlei. The remainder of the tests were all negative.

In view of the current trends in antibiotic research it was thought that a survey of the antibiotic activity of spore-bearing anaerobic bacteria might yield something of interest. A large collection of Clostridium spp. isolated from war wounds was available for this purpose. A preliminary test of a few clostridial species in agar cup-plates, against Mycobacterium phlei, M. smegmatis, and Bacterium coli, revealed the presence of inhibitors of $M$. phlei in cultures of $\mathrm{Cl}$. sporogenes and $\mathrm{Cl}$. bifermentans. The methods of detection and titration of such inhibitors were developed using these strains. At first, the positive results with agar cup-plates were not obtained in repeated tests, although the plates were seeded with varying concentrations of test organisms, and three different media, Fildes's peptic digest (Fildes, 1921), a defined medium (Burkholder \& McVeigh, 1942), and ox-heart extract nutrient agar were used. Titration in tubes, of gradocol membrane filtrates of broth cultures, however, revealed the presence of inhibitors, although in low concentration.

Detectable zones of inhibition on the agar plates were eventually obtained in nutrient ox-heart extract agar, seeded with approximately $0.5 \times 10^{6} \mathrm{M} . p h l e i$ cells $/ \mathrm{ml}$. The cups, 8 or $10 \mathrm{~mm}$. in diameter, were cut with a cork-borer, and were filled with approximately $0.1-0.2 \mathrm{ml}$. of the culture to be tested. The plates were then held at $2^{\circ}$ to enable any inhibitor to diffuse into the medium in adequate concentration before growth of the test organism commenced. The optimum period of chilling was proved to be about $2 \mathrm{hr}$. The plates were incubated aerobically, and it was not therefore necessary to remove the living anaerobic bacteria by filtration because they did not multiply appreciably during the incubation in air. The test cultures were grown in ox-heart extract cooked-meat broth, and after 2 and 6-7 days' incubation, samples were tested in three cup-plates containing, respectively, laboratory strains of $M$. phlei, Staph. aureus 'Oxford' strain, and Bact. coli 88 . The $M$. phlei plates were read after $48 \mathrm{hr}$. incubation, the others after $24 \mathrm{hr}$.

\section{RESULTS}

The species, and the number of strains of each species examined were: Cl. sporogenes $(60) ; C l$. bifermentans (46); Cl. capitovale (18); Cl. welchii (16); Cl. multifermentans (14); Cl. cochlearium (11); Cl. hastiforme (10); Cl. histo- 
lyticum (8); Cl. septicum (8); Cl. tertium (6); Cl. tetanomorphum (5); Cl. oedematiens (3); Cl. tetani (2); Cl. fallax (2); Cl. chauvoei (1); and Cl. butyricum (1). In addition, forty-one strains, not identifiable as any of the above species, were tested; of these twenty-six were 'saccharolytic' and fifteen 'proteolytic'.

Four strains, two of $\mathrm{Cl}$. bifermentans and two of $\mathrm{Cl}$. sporogenes, were weakly active in plates against $M$. phlei, giving zones about $12 \mathrm{~mm}$. overall diameter, corresponding to a titre of $\frac{1}{4}$ or $\frac{1}{8}$ in the tube tests. The production of inhibitors by these strains was, however, variable and did not necessarily occur on subsequent retesting. No inhibition of the staphylococcus or the coliform bacteria was observed.

The feeble activity displayed at times by these few strains did not warrant devising media to manifest the inhibitors with regularity or to produce them in workable quantity. It is possible that with other organisms and other conditions of test, more powerful inhibitors might have been found, but the results suggest that such substances are not generally produced by clostridia. Furthermore, various air-borne contaminants, cocci and bacilli, growing on the cup-plates in the early experiments, showed marked zones of growth stimulation extending into the zones of inhibition, suggesting that many bacteria yield antagonists to the inhibiting substances produced by $\mathrm{Cl}$. sporogenes and $\mathrm{Cl}$. bifermentans.

\section{REFERENCES}

Burkholder, P. R. \& MCVeigh, I. (1942). Synthesis of vitamins by intestinal bacteria. Proc. Nat. Acad. Sci., Wash., 28, 285.

Fildes, P. (1921). A new medium for the growth of B. influenzae. Brit. J. exp. Path. $1,129$. 